\title{
Cultura visual budista: as mudanças da iconografia de Yama e seus significados
}

\author{
Maximiliano Augusto Sawaya* \\ Helmut Renders**
}

\section{Resumo}

Neste artigo apresentamos, primeiro, um estudo comparativo das representações da divindade originalmente védica Yama nas culturas visuais budistas indiana, chinesa, japonesa, tibetana e do sudeste asiático, para depois, estabelecer um diálogo com textos budistas considerados canônicos e não canônicos e com estudos de budólogos como Siklós, Teiser, Zhiru NG, Frédéric. O objetivo é demonstrar como o budismo pela cultura visual articulou a transformação de uma divindade védica cultuada em épocas anteriores ao sistema desenvolvido por Buddha Shakyamuni em uma representação adaptada em culturas distintas às necessidades de seus sistemas de conhecimento da realidade (abhidharma). Como método de interpretação da cultura visual budista recorremos à Wölfflin e Panofsky e Aby Warburg, para identificar os motivos, gestos e atributos centrais e periféricos das figuras e para entende-los nos seus tempos e espaços onde essas representações surgiram.

Palavras-chave: Linguagens religiosas; cultura visual religiosa; budismo; representações de Yama; iconologia.

\section{Buddhist visual culture: changes in Yama's attributes and their meanings}

\begin{abstract}
In this article, we present, first, a comparative study of the representations of the originally Vedic deity Yama in Indian, Chinese, Japanese, Tibetan and Southeast Asian Buddhist visual cultures,; second, we establish a dialogue with Buddhist texts considered canonical and non-canonical and with Buddhist studies such as Siklós, Teiser, Zhiru NG, Frederic. The aim is to demonstrate how Buddhism through visual culture articulated the transformation of a Vedic deity worshiped in earlier times than the system developed by
\end{abstract}

\footnotetext{
* Discente do PPG em Ciências da Religião da Umesp. Contato: maxsawaya@gmail.com.
}

** Docente do PPG em Ciências da Religião da Umesp. Contato: helmut.renders@metodista.br. 
Buddha Shakyamuni into a representation adapted in distinct cultures to the needs of their systems of knowlesge (abhidharma). As method of interpretation of the Buddhist visual culture we use Wölfflin and Panfosky and Aby Warburg to identify central and peripheral motives, gestures and attributes of the figures and to understand them in those times and spaces where these representations emerged.

Keywords: Religious languages; religious visual culture; Buddhism; Yama representations; iconology.

\section{Cultura visual budista: cambios en los atributos de Yama y sus significados}

\section{Resumen}

En este artículo, presentamos, primero, un estudio comparativo de las representaciones de la deidad védica original Yama en las culturas visuales budistas indias, chinas, japonesas, tibetanas y del sudeste asiático, y luego establecer un diálogo con textos budistas considerados canónicos y no canónicos y con Estudios budistas como Siklós, Teiser, Zhiru NG, Frederic. El objetivo es demostrar cómo el budismo a través de la cultura visual articuló la transformación de una deidad védica venerada en tiempos anteriores al sistema desarrollado por Buda Shakyamuni en una representación adaptada en culturas distintas a las necesidades de sus sistemas de realidad abhidharma. Como método de cultura visual budista interpretada, utilizamos Wölfflin y Panfosky y Aby Warburg para identificar motivos centrales y periféricos, gestos y atributos de las figuras y comprenderlos en sus tiempos y espacios donde surgieron estas representaciones.

Palabras llave: lenguas religiosas; cultura visual religiosa; Budismo; Representaciones de Yama; iconología

\section{Introdução}

Os estudos da cultura visual religiosa de lugares conhecidos, porém de tempos anteriores, representam um significativo desafio metodológico. Portanto, estudar a cultura visual de outras culturas religiosas, espaços e tempos é ousado, como, por exemplo, os estudos pós-coloniais sobre o chamado orientalismo europeu nos demonstraram e alertaram. A primeira razão para isso é o caráter polissêmico de figuras e pinturas e das suas linguagens que nos torna vulneráveis de praticar em vez de uma exegese uma eisegese. No caso da cultura visual budista, temos, entretanto, uma ajuda providenciada por textos budistas considerados por seus adeptos canônicos e não canônicos e estudos de budólogos que, ou debatem ou estabelecem compreensões daquilo que a cultura religiosa representa, sem responder todas as perguntas que na perspectiva da cultura visual podem ser levantadas. Portanto, faz sentido de dialogar com estes interlocutores e iniciar uma conversa entre aquilo que se afirma em relação a cultura visual, no caso, de 
uma, incialmente, divindade védica que se chama Yama e aquilo que estes interlocutores oferecem.

Quanto a análise visual, muito precisa ser levado em conta. Isso começa com a própria materialidade dos objetos em estudo que por sua vez depende da capacidade tecnológica e ideológica dos seus criadores ou das suas criadoras. $\mathrm{Na}$ cultura visual não existe um argumentum ex silentio, no mínimo, do silêncio absoluto. Podemos, por exemplo, supor, que existiam antes das imagens estudadas outras imagens parecidas ou relacionadas, mas, perdidas por causa da falta de durabilidade do seu material ou por serem destruídas intencionalmente para apagar a memória. A cultura visual e material trabalha com aquilo que ela tem em seu alcance, nada mais. Muito importante, além da análise detalhada de cada artefato, é também o gênero em si. Uma figura se comunica de forma diferente com seu redor e seu redor com ela, do que uma pintura ou um relevo criado em pedra ou em madeira. Apesar de que há pinturas que quase funcionam como uma figura, por exemplo, os ícones ortodoxos, já que eles reduzem toda informação à própria figura ou ao seu retrato parcial, isso não é o mais comum; pinturas são mais indicadas para narrar uma história de uma representação em relação as pessoas, aos tempos e aos contextos. Pinturas, potencialmente, contextualizam mais, figuras impactam. Pinturas revelam com mais facilidade a provável intencionalidade de uma obra e a negociação que a acompanha.

Entretanto, figuras não se calam plenamente a respeito, já que elas estabelecem seu diálogo com seu observador ou a sua observadora por meios distintos daqueles da pintura. Enquanto a pintura - com a exceção de algo parecido com os ícones ortodoxos - formaliza uma relação mais indireta entre artefato e a pessoa, uma figura tridimensional estabelece uma relação muito mais performativa e direta. Portanto, tem as figuras um papel muito mais elevado e apreciado - ou firmemente rejeitado - nos campos da política e da religião, mas não da filosofia. Inverso a pintura religiosa: por retratar, digamos, também (partes) do imaginário que "envolve" um certo artefato, ela atenda mais exigências filosóficas. Diante dessas alternativas representam os relevos, com as figurações mais complexas, um tipo de pintura em três dimensões, ou seja, um "entre" considerando figuras e pinturas gêneros mais "puros". ${ }^{1}$ Portanto, já entramos em nossa investigação com uma primeira

\footnotetext{
Além disso, requer o uso de relevos de pedra ou de metal - menos de madeira - um conhecimento técnico mais avançado, sem ignorar também que o uso desses materiais transfere também uma intencionalidade, por ser, primeiro, mais apropriado para espaços públicos, expostos à natureza e, segundo, por sinalizar a vontade de uma maior durabilidade da linguagem religiosa articulada.
} 
perspectiva: diante do exposto, esperar-se no budismo mais a apreciação de pinturas e relevos do que de figuras.

Quanto à análise e interpretação das próprias figuras, dos relevos e das pinturas, propomos seguir Heinrich Wölfflin (1864-1945), e aplicar a sua fala focada a explicação de obras da arte às obras de arte religiosa:

Ver é algo que precisa ser aprendido. Não é natural que todos vejam o que há lá. Explicar uma imagem no sentido de que guiar o olho, portanto, é uma parte necessária da instrução histórica da arte. Mas, a palavra tem ainda outros significados. Explicar também significa colocar o fenômeno isolado em seu contexto histórico, pelo qual ele pode realmente se tornar claro. E isso aconteceu, pergunta-se, por que, neste ponto, apenas essa forma de arte se formou, e é por isso? pede novamente uma explicação especial que não é dada na mera descrição da situação (WÖLFFLIN, 1940, p. 7).

Uma segunda distinção de Wölfflin refere-se já ao conjunto de motivos singulares que compõem, especialmente, pinturas e relevos. Wölfflin sugere de procurar identificar um motivo central para depois entender os papeis no conjunto dos motivos secundários (WÖLFFLIN, 1915, cap. 16). Entendemos que esta forma de guiar olhar pode corresponder à arte religiosa budista. Apesar de que no budismo o foco no artista criador deve ser remoto em si, ${ }^{2}$ não seguimos a compreensão da visibilidade pura como uma história de arte de estilos. Para nós estilos não são tão importantes, mas, o nosso interesse se dedica ainda mais aos gestos, símbolos e artefatos integrados na composição de uma imagem ou de uma pintura. Isso era também a compreensão de Erwin Panofsky que entendia tanto as categorias do Kunstwollen artístico como da visibilidade pura, como secundárias. É finalmente, Aby Warburg que não se referia tanto as formas e estilos, como Wölfflin, mas, de gestos como formulas de pathos ou grandes catalizadores de afetos. Em seguida, vamos, primeiro, apresentar as imagens por nós consideradas e procurar identificar qualquer modificação de aspecto iconográficos e iconológicos (perspectiva pré-iconográfica). Na segunda parte, segundo Panofsky, o passo iconográfico, estabelecemos conversas entre textos da época ou anterior a ela.

\section{Contextualização de Yama}

A divindade Yama é uma figura bastante complexa, tanto no budismo quanto nas tradições religiosas anteriores a ele. Isso porque a sua construção se deu a partir de mitos diversos que constituíram uma figura com múltiplos 2 Também não cabe, então, uma ênfase no assunto do Kunstwollen artístico, do querer do
artista de criar algo. 
papéis e significados, que vai desde sua presença em mitos de criação, até senhor dos mundos inferiores (SIKLÓS, 1996); mesmo que essa última tenha se tornado a mais conhecida. Inicialmente, ao ser absorvido pelo budismo, houve apenas a aceitação do culto a Yama (SIKLÓS, 1996, p. 177-178) como algo não contraditório ao sistema de Buddha Shakyamuni. Yama, nessa época, era cultuado como senhor dos ancestrais, senhor e juiz dos mortos (junto com sua irmã Yami ou Yamari), senhor da morte (e, portanto, aquele capaz de impedi-la) como é citado também nos Vedas e em seus comentários (TSAI, 2017c, p. 136-141; SIKLÓS, 1996).

Porém, alguns aspectos de Yama não condiziam com o sistema interdependente budista de interpretação da realidade, como por exemplo, o epíteto de "juiz dos mortos" (uma tradução não literal de dharmaraja) em relação ao conceito de karma ressignificado por Buddha Shakyamuni. Entender Yama como um ser senciente divino - conhecidos como devas e devanis - não é um problema. A cosmologia budista abraça diversos tipos de existências, como podemos ver em alguns sutras, como o Sutra do Bodhisattva Ksitigarbha:

Muitos seres das dez direções do espaço, em seus mundos, e nos mundos adicionais, se juntaram todos no Reino Celestial de Trayastrimsa. E em todos os seguintes reinos celestiais os seres puderam ver também o Buddha Shakyamuni - o reino Catur-meha-raja-kayikas, Tushita, Nirmanarati, Paranirmita-vasavartin, Brahma-parisadya, Brahma-purohitas, Maha-brahmin, e muitos outros numerosos reinos celestiais (TSAI, 2016, p. A.24).

Entretanto, entender que um ser senciente seria capaz de julgar aqueles que morrem, decidindo o renascimento que esses tomariam, é conflitante com o conceito de karma budista. Por essa razão, algumas reinterpretações foram feitas sobre a figura de Yama, como juiz dos mortos (SIKLÓS, 1996, p. 176 e 177).

Com o tempo, Yama passa a ter várias funções e significados dentro do budismo, sendo tratado como um deva, mas também como uma figura simbólica. Como deva, Yama deixa de ser apenas um ser a parte do sistema budista, cultuado por religiosos tanto dentro quanto fora dele, e passa a ter um papel atuante, como um dharmapala, um protetor dos ensinamentos e de seus praticantes, e como um juiz, que supervisiona o processo do karma. Como símbolo, Yama aparece para representar a morte, a impermanência, os processos degenerativos (TEISER, 2008, p. 139-153).

Esses aspectos relacionais de Yama: como deva e como símbolo, estão presentes tanto em textos quanto nas imagens budistas. As principais representações de Yama é como dharmapala, dharmaraja (juiz dos mortos; sendo mais uma testemunha das consequências das ações, dos que um juiz 
Helmut Renders

propriamente dito), mas ele aparece também como deva monstruoso que representa o processo degenerativo da morte e impermanência, significado que permeia também as outras representações.

No primeiro grupo de figuras, investigaremos as imagens, de origens diversas, que aparentemente estão mais relacionadas com as representações védicas e budistas indianas, tanto textuais quanto iconográficas. Já no segundo grupo focaremos na transformação sofrida por Yama na literatura e imagética chinesa, que também influenciou sua representação em outros países.

\section{Levantamento das representações de Yama no budismo asiático e análise pré-iconográfica}

Para a análise, escolhemos representações de Yama de diversos países asiáticos, que tiveram influências budistas. Como veremos, comparando as figuras em seguida, podemos ao primeiro olhar identificar proximidades gerais entre as figuras 1 - 6 e as figuras 8 e 9. Na figura 7 aparece Yama como moldura da roda do renascimento, ou roda [da vida] do Samsara.

Seguiremos a sequência das imagens para a análise pré-iconográfica, mantendo essa sequência na análise iconográfica, mas dividindo em dois grupos, das figuras $1-7$ e da 8 e 9 .

\begin{tabular}{|l|l|l|l|l|}
\hline $\mathbf{N}^{0}$ & Século & Nome & Origem & Fonte \\
\hline 1 & 12 d.C. & Rei Yama. & $\begin{array}{l}\text { Escola Odisha, } \\
\text { Índia. }\end{array}$ & $\begin{array}{l}\text { Museu Nacional de } \\
\text { Nova Délhi. }\end{array}$ \\
\hline 2 & & Rei Yama. & Desconhecida. & Desconhecida. \\
\hline 3 & 9 d.C. & Rei Yama. & Sri Lanka. & $\begin{array}{l}\text { Museu Metropolitano } \\
\text { de Arte, NY. }\end{array}$ \\
\hline 4 & 12 d.C. & Yamaraja. & Japão. & $\begin{array}{l}\text { Museu Nacional de } \\
\text { Shangai. }\end{array}$ \\
\hline 5 & 18 d.C. & Yama. & Tibete. & $\begin{array}{l}\text { Coleção privada, foto } \\
\text { de Bonham. }\end{array}$ \\
\hline 6 & 18 d.C. & Yamaraja e Yami. & China. & $\begin{array}{l}\text { Freer Gallery of Art } \\
\text { and Arthur M. Sackler } \\
\text { Gallery. }\end{array}$ \\
\hline 7 & 19 d.C. & $\begin{array}{l}\text { Roda do } \\
\text { Renascimento. }\end{array}$ & Tibete. & Museu de Arte Rubin. \\
\hline 8 & 10 d.C. & $\begin{array}{l}\text { Ksitigarbha e os Dez } \\
\text { Reis do Inferno. }\end{array}$ & China. & Museu Britânico. \\
\hline 9 & 14 d.C. & Dez Reis do Inferno. & China. & $\begin{array}{l}\text { Museu Nacional de } \\
\text { Nara. }\end{array}$ \\
\hline
\end{tabular}


Figura 1. Rei Yama. Escola Odisha (séc. 12 d.C.).

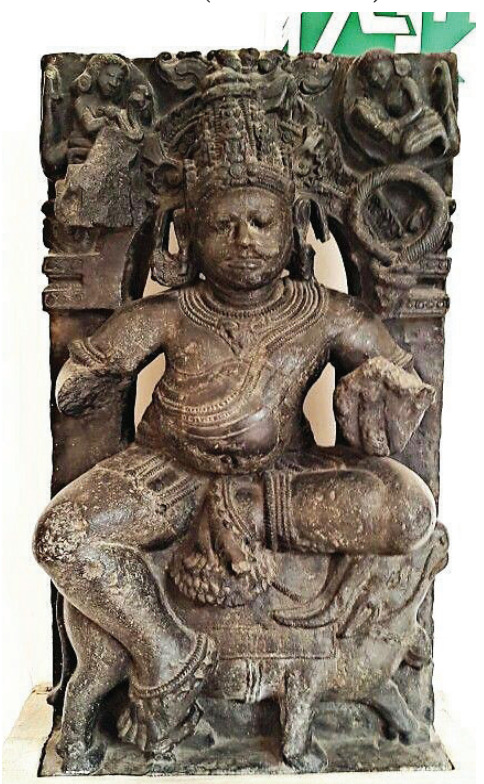

Fonte: Museu Nacional de Nova Delhi ${ }^{3}$.

Figura 3. Yama. Sri Lanka. (séc.9

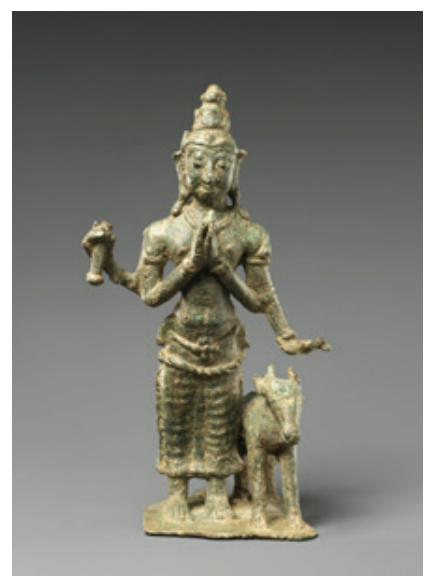

Fonte: Museu Metropolitano de Arte, NY ${ }^{5}$.
Figura 2. Rei Yama.

Origem desconhecida

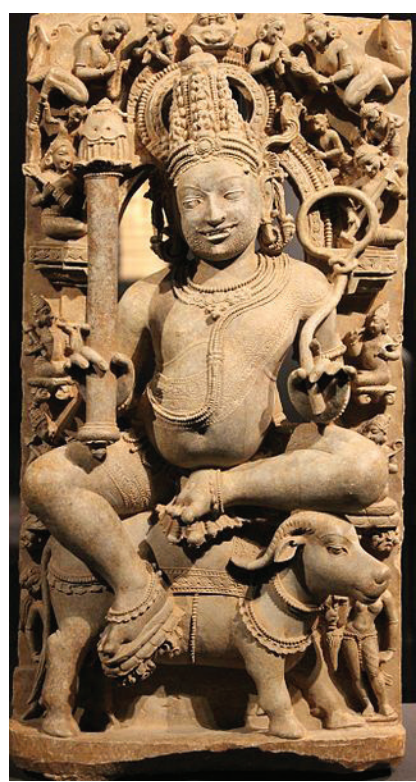

Fonte: Wikimedia ${ }^{4}$.

Figura 4. Yamaraja. Japão, Período de Heian (sec. 12 d.C.).

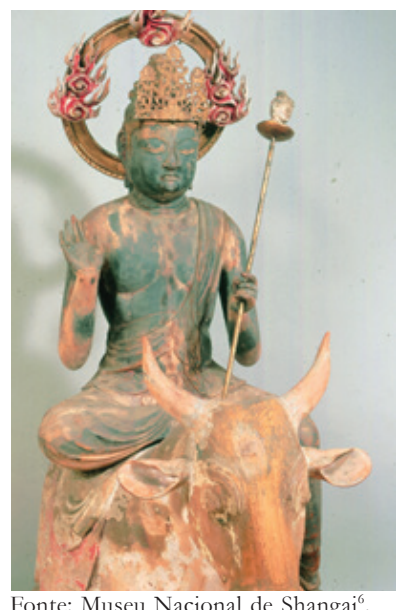

Fonte: Museu Nacional de Shangai ${ }^{6}$.

${ }^{3}$ www.arttreasuresindia.blogspot.com/2015/05/lord-yama.html

${ }^{4}$ www.commons.wikimedia.org/wiki/File:Guardians_of_the_eight_directions_04.JPG

${ }^{5}$ www.metmuseum.org/art/collection/search/72302

${ }^{6}$ www.shanghaimuseum.net/museum/frontend/en/articles/P00004381.html 
Figura 5. Yama. Tibete (sec. 18 d.C.)

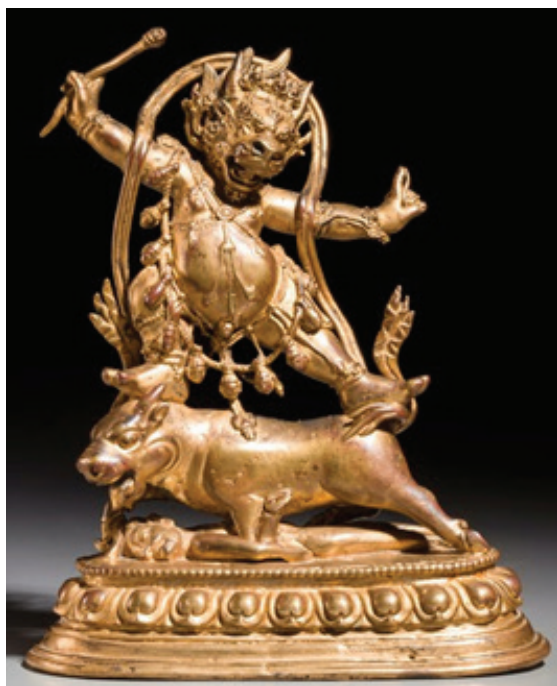

Fonte: Coleção privada, foto de Bonham ${ }^{7}$.
Figura 6 Yamaraja e Yami. China,

Dinastia Qing (sec. 18 d.C.)

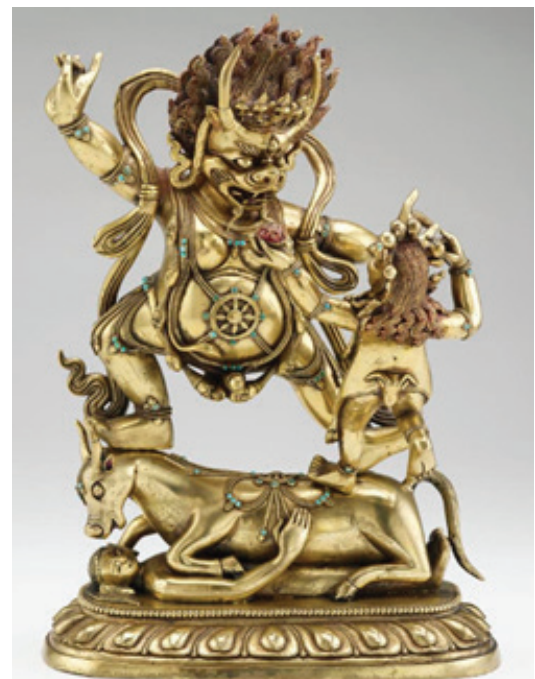

Fonte: Freer Gallery of Art and Arthur M. Sackler Gallery ${ }^{8}$.

Figura 7. Roda do Renascimento. Tibete (sé. 19).

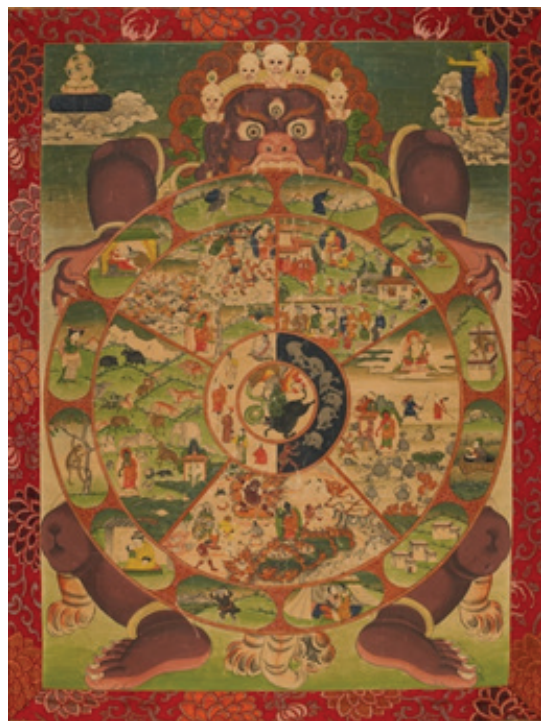

Fonte: Museu de Arte Rubin ${ }^{9}$

\footnotetext{
${ }^{7}$ www.himalayanbuddhistart.wordpress.com/tag/yama-dharmaraja/page/2/\#jp-carousel-14199

${ }^{8}$ https://asia.si.edu/object/S2013.23a-e/

${ }^{9}$ https://rubinmuseum.org/collection/artwork/wheel-of-existence
} 


\section{Grupo 1: Figuras 1 - 7}

Nas duas primeiras figuras, aparentemente dois relevos em suporte retangular de rocha ou argila, vemos um homem, com uma barriga avantajada, sentado em cima de um animal bovino, enquanto o homem está frontalmente representado, o bovino está de perfil. Na figura 1 o bovino está com o focinho erguido enquanto na figura 2 sua cabeça está posicionada olhando para frente. Seu tamanho é desproporcional em relação ao animal, sendo o homem muito maior do que ele. Os pés do homem estão pousados em flores, que servem como suporte. Ambas as pernas estão dobradas, sendo uma completamente dobrada, enquanto a outra levemente.

Ambos usam coroas que se afunilam de baixo para cima, com dez andares, sendo os dois últimos com formato de cuias de boca para baixo. $\mathrm{Na}$ altura das orelhas há apetrechos, não sendo possível reconhecer exatamente que tipo. Há também apetrechos pelo tórax, pernas, braços, como colares, um leve relevo que pode representar tecidos transparentes, braceletes, pulseiras e tornoseleiras.

Na figura 1, o rosto está com os olhos aparentemente fechados, a boca fechada e reta, e representado frontalmente. Na figura 2, o rosto está de semi-perfil, seus olhos parecem abertos, suas sobrancelhas arqueadas, e sua boca levemente arqueada e semi-aberta mostra duas presas afiadas. Além disso, conseguimos ver nas mãos da figura, um porrete e um laço, segurados principalmente com o dedão e o dedo médio, apoiados com o indicador, e com o anelar e o mindinho afastados. Já na figura 1, está faltando o antebraço direito e esquerdo, mostrando apenas a ponta do laço, no relevo atrás, na altura da cabeça.

Os relevos que servem de fundo para a figura do homem e do bovino, são seres humanoides, de tamanho bem menor do que as figuras centrais. $\mathrm{Na}$ figura 1, tem duas figuras aparentemente humanas ajoelhadas segurando algo na mão, em cima do que parecem pilares com um arco que os ligam. $\mathrm{Na}$ figura 2 há mais seres humanoides, iniciando embaixo por mulheres de pé, com o corpo penso para o lado. Elas são seguidas de duas figuras de cada lado, que estão ajoelhadas, mas com o corpo ereto, segurando objetos em suas mãos e com coroas em suas cabeças. Logo acima, no topo dos pilares e no arco que os unem, há aproximadamente sete figuras humanoides tocando instrumentos variados, e o rosto de algum ser de boca larga no centro.

A figura 3 é menos detalhada, sendo feita aparentemente de algum metal, pela coloração. É uma figura humana, com quatro braços, sendo que 
dois dos braços estão dobrados deixando as duas mãos unidas pelas palmas na altura do peito, e os outros dois estão semi-abertos, o do lado direito de quem vê - tem a mão aberta apontando a palma para baixo, enquanto o outro braço está dobrado, com a mão na altura do ombro, segurando o cabo de alguma coisa que está quebrada.

No lugar da coroa, parece ter um cabelo arrumado com dois coques. Ele usa colares, braceletes, pulseiras, uma saia, e apetrechos na orelha. Seu rosto está com os olhos fechados, a boca levemente arqueada para cima e direcionada frontalmente em relação ao seu próprio corpo.

O homem está de pé, com as pernas retas, e com um bovino ao lado, também pequeno em comparação ao homem. Sua cintura é fina e sua barriga não é protuberante como as da figura 1 e 2 .

A figura 4 possui semelhanças com as três figuras anteriores. Seu rosto está com os olhos aparentemente fechados ${ }^{10}$, a boca, nesse caso, está fechada e reta. A direção de seu rosto é frontal em relação ao seu corpo. Ele usa uma coroa tiara com três pontas e, atrás dela, o cabelo preso em coque de dois andares. Ele está sentado no bovino com uma perna completamente dobrada em cima do animal e a outra levemente dobrada ao lado dele.

Diferente das figuras anteriores, esse homem tem um corpo mais atlético, uma auréola com três focos de fogo atrás de sua cabeça. Ele não possui apetrechos em sua orelha nem em seu corpo, vestindo apenas um tecido que cobre seu ombro esquerdo, abdome e pernas. Sua mão direita está aberta na altura do ombro, com a palma apontando para frente, enquanto que a esquerda está na altura do peito, mas distante, segurando levemente um cajado com a cabeça de um buddha na ponta.

As figuras 5 e 6 tem características mais semelhantes entre elas, do que das outras, no que diz respeito a postura corporal e das mãos. Seus dois braços estão esticados para os lados e a mão esquerda, está com o dedo indicador levantado e as pontas do dedão e do dedo médio se tocando; pela imagem, não é possível ver o posicionamento dos dedos anelar e mindinho. A mão direita da figura 5 está segurando um porrete com uma caveira na ponta, enquanto que a da figura 6 , os dedos indicador e mindinho estão levantados, a ponta do dedão e do dedo médio se tocam, e o anelar está na mesma posição que o médio, porém sem tocar o dedão.

\footnotetext{
${ }_{10}$ Aparentemente fechados, pois podem ser também interpretados como semicerrados.
} 
Ambos estão de pé em cima da figura bovina, porém as pernas estão afastadas, sendo que a direita está dobrada e o pé está sobre a cabeça do animal, sem tocar os dedos nele, enquanto a esquerda está estendida e o pé está sobre as ancas do bovino, apoiado sobre seu calcanhar. Ambos os bovinos estão abaixados - ou deitado ou ajoelhado - em cima de uma figura humana. O bovino da figura 5, está com a cabeça reta e a boca aberta, com o cenho franzido e o olho arregalado. O bovino da figura 6, por sua vez, está com o focinho para baixo, como se olhasse para o corpo humano sobre o qual está deitado, com a boca e os olhos abertos. Enquanto Yama está em posição frontal para quem vê, o bovino está de perfil.

Outra grande diferença entre a figura 5 e 6 em relação as suas anteriores, é a cabeça de Yama. Enquanto o seu corpo é humano, com uma imensa barriga tal qual a figura 1 e 2 , seu rosto é de bovino. Na figura 5, com seu rosto em semi-perfil, ele olha para frente, com a boca aberta mostrando seus dentes e língua, seus olhos abertos e cenho franzido. Seus chifres são para cima, tal como os seus cabelos ondulantes. Ambos usam uma tiara com crânios, sendo da figura 5 aparentemente três, enquanto a da figura 6: cinco.

Na figura 6, o rosto também está de semi-perfil, porém olhando para baixo, para uma figura feminina, a qual descreverei mais adiante. Seus olhos estão bem abertos como sua boca também está, mostrando os dentes e a língua. Seu cenho, tal como na figura 5, está franzido, há um terceiro olho em sua testa - o que não fica muito claro na figura 5 - e seus cabelos ondulados estão para cima, assim como seus chifres.

Entre os apetrechos corporais, ele também usa colares, braceletes, pulseiras, tornoseleiras, mas estão nus, não tendo nenhuma representação de tecidos aparentes. Ambas figuras possuem um colar de cabeças humanas. A figura 6, tem adicionada uma roda na frente da barriga, com oito aros.

Outra grande diferença entre a figura 6 e a 5, é que a primeira tem a presença de uma figura feminina, nua, de cabelos compridos e soltos, uma tiara com o que parece ser crânios, com um braço quase completamente esticado, segurando em sua mão algo que parece uma cuia com coisas dentro. O braço esquerdo dela está dobrado, sua mão está na altura da cabeça com o indicador e o mindinho erguidos, não sendo possível ver a posição exata dos demais dedos, mas dando a impressão de ser o mesmo gesto que a mão direta do homem. Uma perna dela, a esquerda, está quase completamente esticada, tendo seu pé apoiado sob a anca do bovino, e a outra, a direita, está dobrada e a sola do seu pé a mostra. 


\section{Maximiliano Augusto Sawaya}

Helmut Renders

Tanto na figura 5 quanto na 6, o corpo humano deitado, o bovino, o homem e a mulher - apenas na figura 6 no caso - estão sobre um chão circular de superfície plana, que fica em cima de uma flor com várias pétalas. E essa flor está posicionada em cima de outro suporte.

A figura 7, é uma pintura colorida, mostra um ser humanoide de cor marrom segurando uma roda cheia de detalhes. Esse ser tem três olhos esverdeados e arregalados, olhando para a frente com o cenho franzindo, dentes a mostra mordendo a roda. Ele usa uma tiara com cinco caveiras, seus cabelos alaranjados são ondulados para cima. Ele tem unhas compridas como garras, tanto nas mãos quanto nos pés. Patas de tigre aparecem perto de sua perna e entre elas, dando a impressão de que ele está vestindo uma pele da cintura para baixo. Ele usa apetrechos como brincos, tornoseleiras, braceletes e pulseiras. Como nosso principal foco é Yama, não haverá descrição das figuras dentro da roda.

\section{Grupo 2: Figuras 8 e 9}

A figura 8 é uma pintura com diferentes tons de marrom, do avermelhado ao alaranjado, tendo também tons de vermelhos e salmão. Nela há um homem sentado no centro, maior em tamanho do que todas as outras figuras humanas que o rodeiam. Esse homem segura na mão esquerda - que está próxima de sua perna - um bastão em vertical. Sua mão direita, próxima ao joelho do mesmo lado, segura um objeto circular branco, o que parece ser colar de contas.

Ele veste na cabeça um turbante, que cobre suas orelhas, e seu corpo está completamente vestido com diversas camadas de tecidos. Em seu peito é possível ver um colar com joias, e pulseiras em seus pulsos. Ele está sentado em um tapete, suas pernas estão dobradas, sendo a esquerda mais dobrada que a direita, que está apenas semidobrada. Seu pé esquerdo toca sua perna direita, enquanto seu pé direito está apoiado em uma flor. Atrás dele há um círculo de fogo maior, de suas pernas até a cabeça, onde é sobreposto por um círculo de fogo menor, que parece estar atrás do ombro até acima de sua cabeça.Obviamente, a pintura não utiliza técnicas de perspectiva renascentistas, e, portanto, o que parece estar abaixo dele, é passível de ser interpretado como estando na frente. Sendo assim, a sua frente vemos um leão branco, um homem com túnica marrom escura e com as mãos unidas pelas palmas na altura um pouco acima de seu peito. Mais a frente, vemos um ser humanoide, com cabeça que lembra um bovino, vestindo apenas 
Figura 8. Ksitigarbha e os Dez Reis do Inferno. China (séc. 10 d.C.).

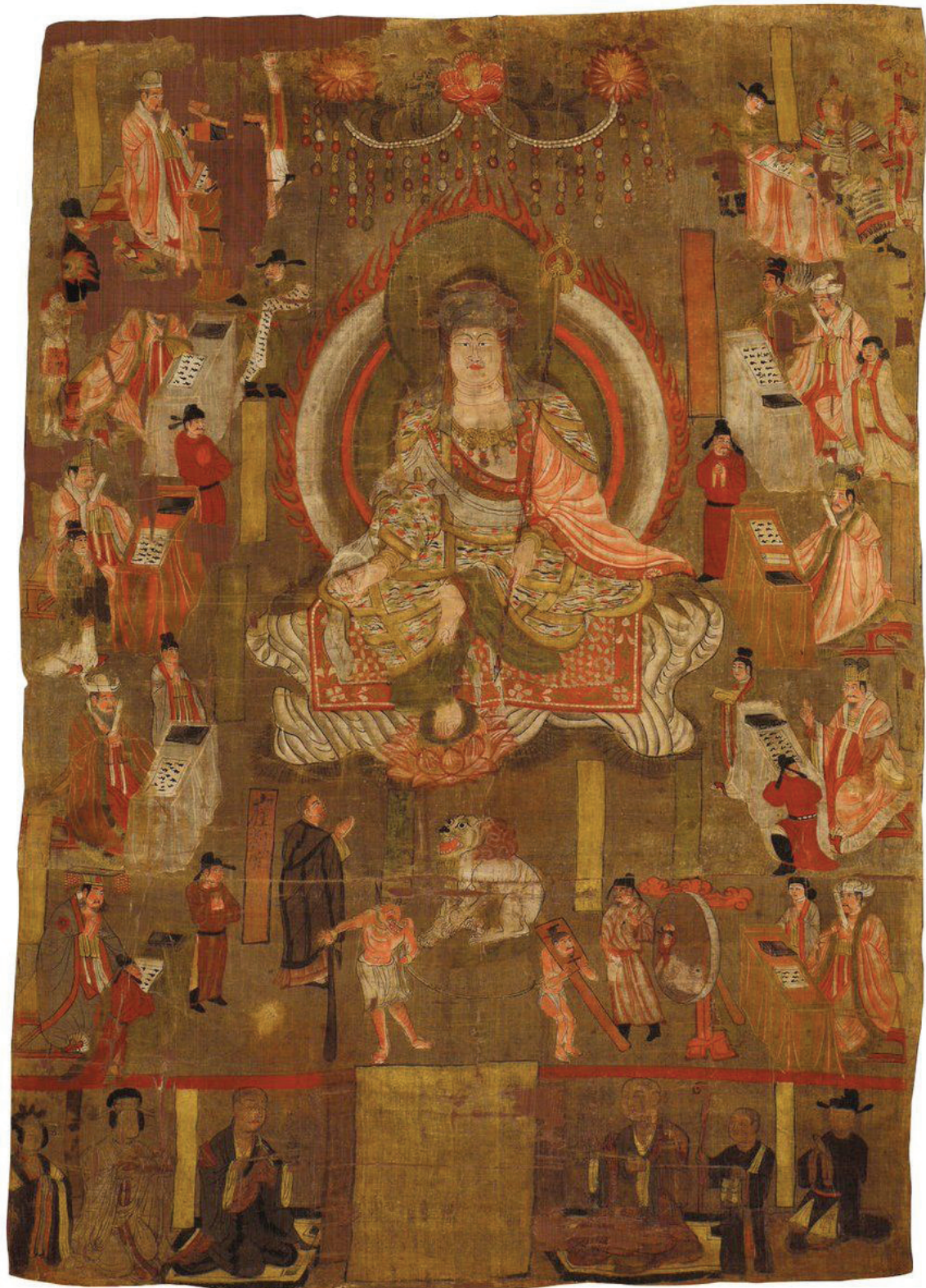

Fonte: Museu Britânico ${ }^{11}$. 11 www.research.britishmuseum.org/research/collection_online/collection_object_details.aspx?assetId
$=1613035367 \&$ objectId=6568\&partId=1 
Figura 9. Dez Reis do Inferno. China (séc. 14 d.C.).

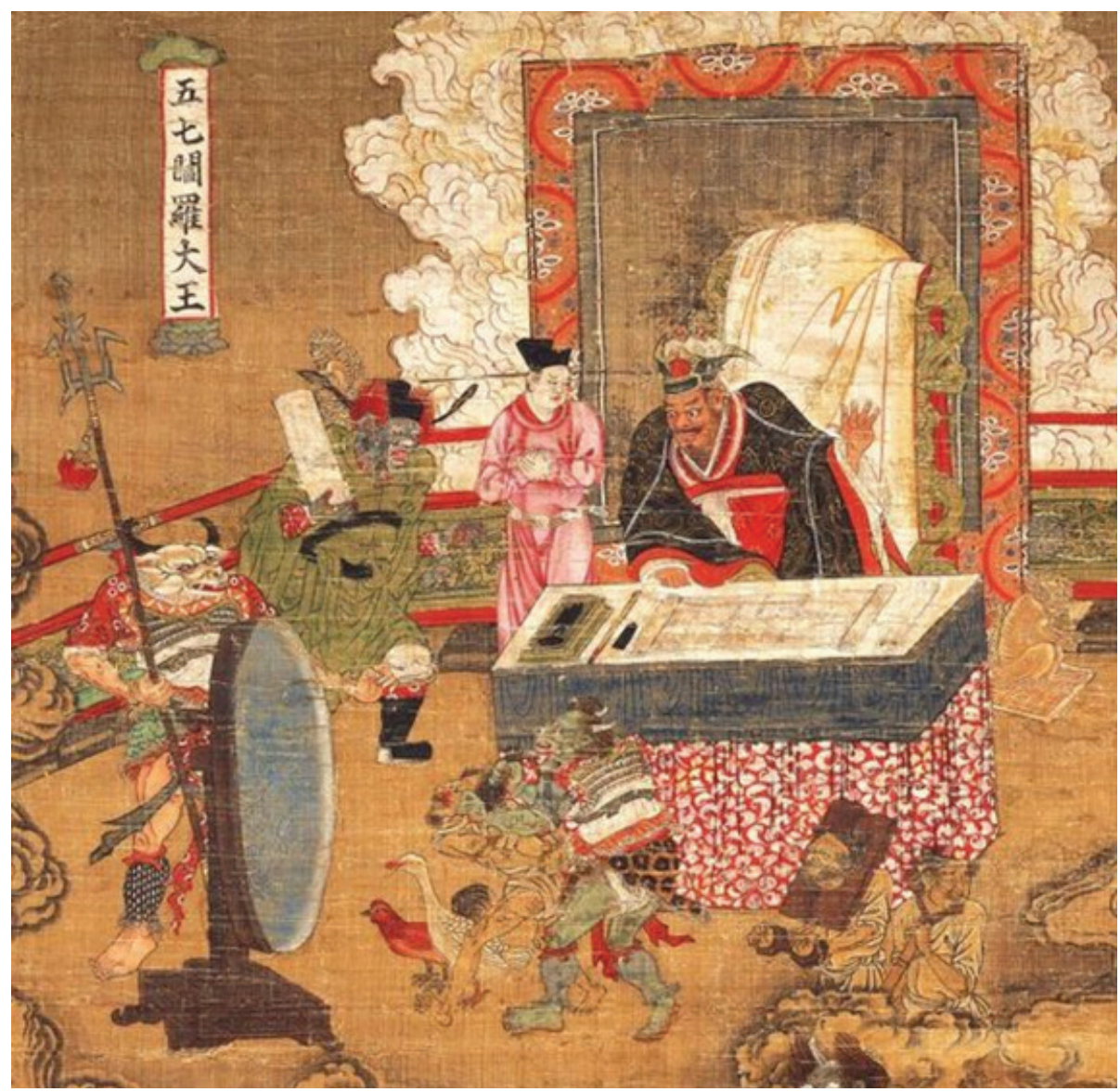

Fonte: Museu Nacional de $\mathrm{Nara}^{12}$

uma canga branca e segurando em sua mão direita um porrete, e em sua mão esquerda um laço, que está amarrado no pescoço de um homem, que se encontra mais ao lado direito da pintura para quem está vendo, e que tem, também, seu pescoço preso a um objeto quadrado. Esse homem está na frente de um objeto circular, com imagens borradas dentro. Ao lado do objeto circular, está um homem com chapéu preto e uma túnica branca, com linhas marrom avermelhado.

${ }^{12}$ www.narahaku.go.jp/english/collection/1006-0.html 
Atrás desse objeto, mais ao lado direito da pintura, há uma mesa com pergaminho, um livro, e atrás da mesa está um homem sentado, com chapéu branco, vestindo muitos tecidos, semelhante aos que vemos também nas figuras 9. Ao seu lado está sentada o que parece ser uma mulher. Esse homem é o primeiro - de baixo para cima - de uma sequencia de homens atrás de mesas, acompanhados por outros homens e mulheres. Nessa sequencia há, do lado direito da pintura para quem está vendo, cinco homens sentados atrás de uma mesa. Sendo que apenas o primeiro de cima, que veste uma armadura ao invés de túnicas. Imagens de homens semelhantes se repetem no lado esquerdo, contando-se também cinco homens, que contam com ajudantes de diversos tipos.

Mais a frente do homem central, na parte debaixo da figura, vemos mais seis seres humanos, ajoelhados, sendo três com chapéu e cabelo, e três carecas. Dois deles, um do lado direito e outro do lado esquerdo da pintura, estão ajoelhados em cima de uma plataforma.

A figura 9 também é uma pintura com tons semelhantes aos da pintura 8 , porém com mais presença de vermelho e cinza esverdeado. Há também semelhanças nas vestimentas, quando comparados aos homens sentados atrás de mesas ao redor da imagem central da figura 8.

Aqui na figura 9 vemos um homem, com chapéu branco, cinza e com um círculo vermelho no centro, vestindo tecidos preto, vermelho e branco. Sua mão esquerda está aberta e erguida na altura do ombro, enquanto a direita está apoiada na mesa, próximo a um pergaminho aberto - que ocupa quase toda a mesa - e um livro fechado. Seus olhos estão arregalados, voltados para um objeto cinza circular, localizado no canto inferior esquerdo da pintura. Do seu lado direito há um ser humano, com túnica vermelha e rosa, vestindo chapéu preto, com o rosto voltado para o homem atrás da mesa. Ao lado desse ser humano vestido de rosa com vermelho, vemos um ser humanoide não identificável, segurando um objeto cilíndrico branco em sua mão direita, vestindo um chapéu preto e vermelho, e uma túnica cinza esverdeada.

Atrás do objeto circular cinza, com um suporte marrom escuro que o mantém de pé, há um ser humanoide, vestindo um peitoral de armadura, com cabeça bovina, segurando um tridente exótico. $\mathrm{Na}$ frente desse mesmo objeto, vemos um ser humano amarrado, sendo segurado por trás por uma criatura humanoide vestindo armadura, enquanto que na sua frente, bem próximo a ele, há um pato e um galo. Atrás da criatura humanoide com armadura, bem no canto inferior direito da pintura, estão dois homens presos: um por 
Helmut Renders

um objeto de madeira retangular no pescoço e com algemas nas mãos, e o outro com uma corda no pescoço. O homem com a madeira retangular está olhando em direção dos seres a sua frente, enquanto o homem com a corda no pescoço, está olhando para trás.

\section{Análise iconográfica do Primeiro Grupo}

Uma das representações de Yama adotadas nos textos budistas é o de dharmapala (protetor dos ensinamentos e dos praticantes). O dharmapala Yama é associado ao aspecto de deus da morte, rei dos Reinos Miseráveis, chamado de Yamaraja (sansc.: Rei Yama ou Imperador Yama).

Dentro da mitologia budista, Yama é o Imperador dos Reinos Miseráveis vindo do Maha-cakravala (TSAI, 2016, p. A.46), que comporta os reinos miseráveis de maior sofrimento. Mas, ao contrário do que nosso senso comum pode nos dizer, ele e seu secto de reis-yamas, não são descritos como seres que gostam do sofrimento que os seres passam por lá, mas como alguém que tenta ajudar aqueles seres angustiados.

Todos esses maha-raja-raksas, juntamente com numerosos raja-raksas, chegaram até o Reino Celestial junto com o Imperador Yama para prestarem homenagem ao Buddha. Esses raja-rakshas, bem como aqueles dos grupos inferiores possuem diferentes responsabilidades, ou para corrigir aqueles que realizam ações aflitivas ou para trazer felicidade e beneficiar aqueles que praticam virtudes (TSAI, 2016, p. A.47).

É no final do trecho citado do Sutra do Bodhisattva Ksitigarbha, que dois dos papeis de um dharmapala é exposto. Papeis esses que são adotados pelos bodhisattvas ${ }^{13}$ da tradição Mahayana. Sendo assim, Yama como um dharmapala mantém seu aspecto de imperador, só que agora, um imperador bodhisattva.

13 No código moral dos bodhisattvas, presente no texto: Os Três Tipos de Compromissos do Bodhisattva, encontramos compromissos que mostram esses papeis de um dharmapala. Há compromissos que dizem respeito a beneficiar e a corrigir, como: agir de maneira correta pelo bem da motivação dos outros; manter uma conduta moral que busca ajudar no aumento da felicidade dos seres sencientes; agir para remover o sofrimento dos outros quando possível; retribuir a bondade; trabalhar para o bem-estar dos alunos; dar treinamento rigoroso de acordo com as condições, disciplinar, usar métodos corretivos; etc. Veja: TSAI, Plínio. Cerimônia do Uposatha: de acordo com o Pratimoksa Mulasarvastivada. Valinhos: ATG, 2017, p. 105-118. 
A versão indiana de Yama pode ser descrita como um rei, montado em um búfalo, segurando em sua mão direita um porrete (sansc.: danda), e em sua esquerda um laço (figura 1 e $2^{14}$ ). As construções textuais de Yama, que se relacionam com a figura do rei, são diversas, o que não ocorre com o búfalo, que é mais escasso. A relação entre Yama e o búfalo, por exemplo, parece não ser direta, sendo traçada em tradições anteriores aos Vedas, e que influenciaram mitos de outras culturas indo-européias (SIKLÓS, 1996).

Nos Vedas, livros sagrados do Brahmanismo, mais especificamente no $\mathrm{Rg}$-Veda e Atharvaveda-sambita, o nome de Yama aparece nas seguintes situações: como gêmeos ${ }^{15}$ (Yama e Yami ${ }^{16}$ ) em uma tentativa de incesto por parte da irmã, e como primeiro ser a experienciar a morte e senhor do mundo dos mortos (SIKLÓS, 1996, p. 169; GRIFFITH, 1896). Entretanto há indícios linguísticos que relacionam Yama ao mito de criação presente também no Rg-Veda (GRIFFITH, 1896, livro 10 hino 90 versos 1-16). Esse texto, conta sobre o sacrifício de Purusa (sânsc.: homem), possuidor de mil cabeças, olhos e pés, que é desmembrado e suas partes oferecidas pelos devas para o surgimento de um novo mundo e tudo que ele contém, inclusive as castas (SIKLÓS, 1996, p. 165).

Mitos semelhantes ocorrem em algumas culturas do tronco linguístico indo-europeu. Tal como no mito iraniano do búfalo / Gayomart e o mito nórdico de Ymir. No mito iraniano, a criação se dá com dois sacrifícios: de um búfalo e de Gayomart, um homem, o que influi na iconografia de Yama e que vemos na construção da palavra Purusa (pu [pu-man "humano" ou pu-tra "filho"] + vrsa ("búfalo"; por metátese passa-se para rusa) (SIKLÓS, 1996, p. 167). Enquanto que o mito nórdico é semelhante ao de Purusa, no qual Ymir, ancestral dos humanos e gigantes, é sacrificado e desmembrado por Odin, Vili e Ve, levado para o espaço vazio (Ginnungagap) e usado para fazer o mundo. O nome Ymir é um cognato de Yama, segundo Siklós (1996, p. 166-167). Já Frédéric (1995, p. 253) relaciona a presença do búfalo na iconografia de

14 Inclui a figura 2, mesmo sem ter informação sobre a origem da imagem, como complemento da figura 1 , já que nessa alguns pedaços estão faltando.

15 No artigo The Evolution of Buddhist Yama, o budólogo Siklós esclarece que um dos significados da palavra Yama em sânscrito é "gêmeos", trabalhando outros significados que foram sendo atribuído a esse nome, relacionando com suas diversas funções (cf. SIKLÓS, 1996, p. 165-189).

16 Um dos significados para Yami é "irmã", como aparece no dicionário online de sânscrito: spokensanskrit.org. 
Yama com o mito, posterior aos citados, de Durga expulsando um "demônio da morte" representado como um búfalo.

Parece que, por conta dessa possível relação entre os mitos de Purusa, Gayomart e Ymir, que o búfalo ficou associado a Yama. No Rg-Veda, não há descrição de nenhuma montaria dessa divindade, nem o relaciona com um búfalo. Enquanto que no Atharvaveda-sambita, a montaria que é descrita é um cavalo marrom, enquanto o búfalo é usado como adjetivo metafórico para vários deuses do panteão védico (GRIFFITH, 1896).

A coroa e o porrete, muito provavelmente, está relacionado com sua condição real, já que essa era uma posição própria dos ksatriyas (a casta guerreira) (TSAI, 2017c, p. 142), mas não encontrei nenhuma referência textual que afirma isso, mesmo que sua condição real seja tratada tanto no $\mathrm{Rg}$-Veda quanto Arthavaveda-sambita, como rei do mundo dos mortos e dos ancestrais, e mantido como senhor da morte na literatura budista Mahayana como no Sutra do Bodhisattva Ksitigarbha, quanto no texto Vajrayana tibetano "Bar do thos grol (Liberation through hearing in the intermediate state)" (SIKLÓS, 1996, p. 178).

Já o laço está presente no livro dos Vedas, especificamente no Atharvaveda-sambita, onde Yama é descrito como possuidor de uma corrente, tanto literalmente, "Liberte-me daquilo que vem de uma maldição, e também daquilo que é de Varuna, então dos grilhões de Yama, de todas as ofensas contra os deuses" (WHITNEY, 1905, p. 351), quanto metaforicamente, "Deixe a perdição amarrá-los, com os inquebráveis grilhões da morte" (WHITNEY, 1905, p. 93).

Mesmo que esses implementos - o laço e o porrete - não sejam mencionados nos textos budistas Mabayana Paramitayana ${ }^{17} \mathrm{e}$, aparecem na literatura Vajrayana, eles são mantidos na iconografia budista do Yamaraja (SIKLÓS, 1996, p. 183). Em algumas imagens podemos ver também características iconográfica de bodhisattvas inseridas nas representações de Yama, como por exemplo o anjali mudra (fig. 3) - as duas mãos juntas pelas palmas -, que normalmente simboliza um gesto de "oferenda e veneração", presente na iconografia de bodhisattvas e raramente de buddhas (FRÉDÉRIC, 1995, p. 48).

Outro aspecto são os olhos semicerrados de conotação meditativa (fig. 3 e 4), mesmo que sua postura não seja aquela relacionada diretamente a concentração meditativa, como é o caso da padmasana, postura dos lótus ${ }^{18}$

\footnotetext{
17 A tradição Mabayana Paramitayana é a vertente não tântrica, focada no desenvolvimento das perfeições de superação, Paramitas.

18 Postura de pernas cruzadas, normalmente associadas com a prática de meditação.
} 
(FRÉDÉRIC, 1995, p. 55). Yama é comumente representado na postura de lalitasana, sentado com uma perna tensamente dobrada e a outra relaxada (fig. 1, 2 e 4); postura essa bastante relacionada a bodhisattvas. As vezes também, mas bem mais raramente, ele é representado na postura kayotsarga, estática em pé (fig. 3), pois as pernas juntas e eretas dão a impressão de não estarem em movimento (FRÉDÉRIC, 1995, p. 53 e 56).

Já, na iconografia Vajrayana, principalmente indo-tibetana e sinotibetana, onde ele é um dos oito protetores irados da religião (SIKLÓS, 1996, p. 183), há a inclusão de uma cabeça de búfalo, ao invés de uma cabeça humana, e sua postura, ardhaparyanka (FRÉDÉRIC, 1995, p. 57), é mais dinâmica, dá a impressão de que Yama está dançando sobre o búfalo aos seus pés (fig. 5 e 6). Mesmo com a inclusão da cabeça de búfalo, o animal externo não foi removido em alguns casos.

No Vajrayana, a imagética é usada como ferramenta meditativa, as vezes catafática, com os buddhas e bodhisattvas pacíficos, ou apofática com os buddhas e bodhisattvas irados. No caso da cabeça de búfalo irado de Yama, o ferramental é apofático, tal como ocorre com Yamantaka:

"No Vajrayana temos um processo apofático de desconstrução refletida sobre uma imagem daquilo que não é. Por exemplo, a imagem de Yamantaka é de um búfalo furioso, que os chineses passaram a interpretar como um dragão furioso, mas Yamantaka, que quer dizer o destruidor da morte, no sentido de destruidor do ódio que leva para as ações homicidas e destrutivas, reflete na sua figura exatamente aquilo que ele não é.” (TSAI, 2017ª p. 29)

Do mesmo modo, Yama, quando passa a ser um bodhisattva protetor dos ensinamentos e de seus praticantes, adota uma postura de compaixão, buscando beneficiar os seres através de ajudas ou de correções, como vimos anteriormente. Sendo assim, ele também não é um búfalo furioso e sanguinário.

Outra característica incluída algumas vezes é a presença de Yami, ou Yamari (fig. 6), também deusa da morte, que ajuda Yama em seus julgamentos (FRÉDÉRIC, 1995, p. 253). Yami, na mitologia védica, é a irmã gêmea de Yama, que, como é contado no $\mathrm{Rg}$ - $V e d a$, tenta seduzir seu irmão para se relacionar sexualmente, mas não é bem sucedida (GRIFFITH, 1896, livro 10 hino 90 versos 1-16). Há um mito iraniano semelhante, presente na coleção litúrgica do Zoroatrismo, Yasna, sobre o rei Yima e sua irmã gêmea que busca seduzi-lo, mas nesse caso ela é bem sucedida, o que resulta na mortalidade dos seres humanos (SIKLÓS, 1996, p. 168-169). 
Nos textos budistas, é nos tantras que Yami aparece nas descrições imagéticas do que é chamado de Forma Externa de Yama, que faz parte de um grupo de três representações: Forma Externa, Forma Interna e Forma Secreta. Nas representações da Forma Externa (fig. 6), Yami “oferece a ele (Yama) uma cuia de crânio cheia de sangue com sua mão direita" (SIKLÓS, 1996, p. 183).

As três formas de Yama no Vajrayana também tem significados meditativos como exposto por Siklós: "Essas três formas podem parecer elaborações tardias da exegese Tantrica, mas elas são propostas para serem entendidas em termos de vários aspectos e consequências da própria morte." ${ }^{19}$ (SIKLÓS, 1996, p. 184) Citando, posteriormente, Vimalaprabha (séc. XI d.C.): "os pretas que habitam nos lugares, o senhor da morte que está no corpo, as degenerações (klesa) que estão na mente."20 (SIKLÓS, 1996, p. 184).

Portanto, o Yama externo, tanto quanto os Yamas internos e secretos, são objetos de meditação. No caso da Forma Externa, que representa seres externos, podemos associar com um evento da vida do Buddha, onde ele usa o medo que seus alunos sentem de ser atacados por demônios, como objeto de meditação para eles desenvolverem ainda mais determinação em suas práticas:

Alguns lhes disseram que eles temiam que os demônios viessem a perseguilos e os derrotassem porque eram realizados somente em nome, mas não de fato. E o Buddha lhes disse novamente para continuarem a praticar, a meditar, a estudar e a ensinar, até que as aflições e delusões desaparecessem, e assim eles venceriam um dos tipos de demônios, aqueles demônios interiores que só existem na interdependência com os próprios praticantes (TSAI, 2017b, p. 159).

Outro aspecto de Yama, presente nesse primeiro grupo de imagens, representado no budismo é como símbolo da morte e impermanência, normalmente associado a Bhavachakra, roda da vida, ou Samsarachakra, roda do samsara (fig. 7). Nesse caso não há um ser senciente sendo representado, mas um processo degenerativo, um conceito abstrato, representado na forma de um monstro que agarra a roda da existência aflitiva.

Agarrando com suas garras a roda inteira, está o Grande Demônio da Impermanência. Essa pintura retrata o demônio como Yama, o supervisor

19 "These three forms may seem to be the elaborations of later Tantric exegeses, but they are intended to be undertood in terms of various aspects and consequences of death itself."

20 "the preta dwelling in the place, the lord of death which is in the body, the defilements (klesa) which are in the mind." 
das regiões infernais na mitologia Budista. Por colocar os seis caminhos (de renascimento) sob o controle de Yama, que em outra forma reina os reinos mais miseráveis de renascimento, a pintura mostra como todas as formas de vida são alvos inevitáveis da dor ${ }^{21}$ (TEISER, 2008, p. 141).

Aqui, o rosto de Yama é o de um ser feroz, mas mais próximo do humano. Ele não tem nenhum dos apetrechos que vimos anteriormente, apenas uma coroa de caveiras. Seu ato de segurar a roda pode ser associado aos objetos de meditações: morte e impermanência, e como as aflições dos seres sencientes dos seis reinos (devas, ashuras, manasvins [humanos], tiryaks, pretas e naskaras, representados dentro da roda) os mantém presos ao processo degenerativo chamado de samsara.

Mesmo tendo tudo na vida,

Milhares de homens e mulheres de toda sorte,

E de todos os caminhos da vida,

Necessariamente todos estão sob o poder da morte

(DHARMATRATA, 2018, p. 18).

Entretanto, como visto na Figura 7, há um buddha fora do poder de Yama, representando a paz definitiva, nirvana, como um processo distinto da degeneração, mas há também os buddhas representados em cada reino, simbolizando os meios habilidosos para ajudar a todos os seres a realizarem também a paz definitiva (TEISER, 2008, p. 139-141).

Sendo Yama apresentado como um processo degenerativo e esse como sendo causado pelas aflições, a escapada final de suas garras, advém da cessação dos estados aflitivos, klesas, que é interpretado como um dos tipos de maras, traduzido normalmente como demônios.

Assim é, cultive alegria na estabilidade,

Coloque-se em meditação equilibrada, faça esforços.

Olhe para o final da vida e veja a morte,

Destrua completamente todas as classes de demônios!

Ó monges! Façam assim e superem a vida e a morte!

(DHARMATRATA, 2018, p. 23).

21 "Grasping the entire wheel in his claws is the Great Demon of Impermanence. This painting portrays the demon as Yama, the overseer of the hell regions in Buddhist mythology. By placing all six paths under the controlo $f$ Yama, who otherwise rules the lowest realm of rebirth, the painting shows how all forms of life are unavoidably subject to pain" 
A superação dos maras, nesse contexto, é a superação de Yama, o que também estabelece como plausível a interpretação de que o monstro que segura a roda, é Mara (TEISER, 2008, p. 149). Para Siklós, Mara é uma manifestação de Yama, além de ser exclusiva do budismo (SIKLÓS, 1996, p. 179). Para ele há uma relação por conta do enfrentamento ao sofrimento existencial da morte. Além disso, um dos mitos de cultura indo-europeia associados a Yama, estabelece Mara como um subordinado dele. Na religião dos Kafirs, - uma religião pré-védica, presente na cordilheira Hindu Kush, no Afeganistão e Pakistão - Imra, associado a Yama, era visto como o deus supremo, que regia tanto o mundo superior (Urdesh) pessoalmente, quanto o mundo inferior (Yurdesh) através de um representante: Maramalik, associado ao Mara, presente no budismo (SIKLÓS, 1996, p. 172).

A representação da samsarachakra, roda do samsara, sofre alterações cosmológicas na China. Por um conflito com a cosmologia dos mitos chineses, a roda presa por Yama vai sendo alterada para um processo burocrático de renascimento. Os seis reinos permanecem, mas agora, é Ksitigarbha, um bodhisattva, que lidera um grupo de reis dos reinos dos mortos, em um julgamento justo por estar sendo guiado por compaixão (FAURE, 2013; TEISER, 1988 e 1993).

\section{Análise Iconográfica do Segundo Grupo}

Yama como juiz dos mortos, aparece no imaginário védico, pré-budista, nos comentários dos Vedas chamado Brahmana (SIKLÓS, 1996, p. 175). Esse é o aspecto mais conflitante de Yama com o sistema budista, principalmente no que diz respeito a interdependência, pratityasamutpada $a^{22}$ (TSAI, 2017c, p. 76), e as relações causais presentes nesse sistema, o que inclui a teoria do karma.

As coisas em suas relacionalidades geram efeitos, e esses efeitos podem ser controlados pelo homem a partir de uma compreensão da causalidade. Então os efeitos que o homem pode controlar e nos quais ele tem participação direta são formados a partir de causas nas quais ele pode atuar (TSAI, 2017c, p. 76).

22 Segundo Plínio Marcos Tsai: “A interdependência é o que o homem pode conhecer da relacionalidade de todas as coisas, mas não de maneira geral, como se houvesse a possibilidade de uma onisciência divina, ao contrário, é aquilo com que ele pode se relacionar dentro de suas limitações como homem, como ser-relações, dentro da impermanência". Veja: TSAI, Plínio Marcos. História da Tradição Budista Indiana. Valinhos: ATG, 2017c, p. 76. 
A partir dessa premissa da interdependência, o karma, na reconstrução do conceito feito pelo Buddha, não diz respeito a destino e nem a decisão de seres externos sobre os efeitos que surgem nas relações causais. Yama, como juiz dos mortos, perde parte de seu poder, e passa a ser visto como uma testemunha das ações e suas consequências naqueles que falecem. Isso, no budismo chinês, por volta do século X d.C., com a composição do texto A Escritura dos Dez Reis dos Infernos, feita pelo monge Tsangch'uan (TEISER, 1993, p. 628), que influenciou a imagética do budismo de outros países como o japonês e o vietnamita, por exemplo, mostra - tanto textualmente quanto imageticamente - Yama (chin.: Yanluo; jap. : Emma-o) como um burocrata da quinta esfera do mundo dos mortos (fig. 8 e 9), responsável por relatar as ações dos mortos e suas consequências, vistas no espelho do karma (fig. 8 e 9) (TEISER, 1993; SIKLÓS, 1996; FAURE, 2014).

A proposta do samsarachakra, que estabelece um fluxo natural, sem a intervenção de divindades, nem mesmo o Imperador Celestial, muito importante para o Taoísmo, parece ter incomodado a imaginação chinesa. Ainda assim, ter alguém que decidisse pelo destino dos mortos, não estaria completamente de acordo com a perspectiva budista do karma.

Nesse contexto, Yama (Yanluo) não decidia mais os futuros renascimentos dos seres, mas garantia parcialmente que a justiça fosse feita: que cada ser tivesse o renascimento condizente com os efeitos de suas ações. Por essa razão, ele não é mais retratado como um rei, um imperador, alguém que porta o poder de decisão, mas como um magistrado chinês, que toma suas decisões através de processos burocráticos de julgamento. Yanluo também conta com assessores, um deles tendo cabeça de búfalo e outro com cabeça humana (FRÉDÉRIC, 1995, p. 253), ou em algumas representações com cabeça de cavalo, o que se comunica com a iconografia do Yama indiano como presente no Atharvaveda-sambita (WHITNEY, 1905, p. 229).

Não são em todas as representações que está presente o espelho do karma (fig. 8 e 9). Entretanto, quando esse está representado, não é Yanluo que o porta, mas seus assessores que o utilizam levando o morto para ver seu próprio reflexo, como em um tribunal onde ele está sendo julgado por Yanluo. Esse utensilio é baseado em uma metáfora presente em uma lenda amplamente divulgada sobre o aluno do Buddha, Maudgalayana, que vai aos reinos miseráveis ajudar sua mãe (NG, 2017, p. 154-156). No espelho do karma, diz essa mitologia budista, aparecem tudo sobre as ações daquele que olha seu reflexo nele (FAURE, 2013, p. 86). Esse espelho do karma 
costuma ser representado com o assistente com cabeça de búfalo portando-o ou próximo a ele (fig. 8 e 9), enquanto um morto que está sendo julgado é levado a ver seu reflexo por outro assistente. Yanlou observa atentamente o que está acontecendo, como se estivesse aguardando para dar seu julgamento.

Esse processo de renascimento burocrático, desenvolvido com o contato da cosmologia budista, taoísta e confucionista, que influenciou também a imagética de outras escolas budistas do extremo oriente (SIKLÓS, 1996, p. 182), mesmo que se distanciando um pouco da perspectiva do pósmorte budista anterior, ainda trouxe questionamentos para a mentalidade budista chinesa. O que garantiria que os dez reis, que inclui Yanluo (Yama) - o quinto rei - não cometeriam enganos? É esse questionamento que os levou a incluir o bodhisattva Ksitigarbha (fig. 8) como senhor do mundo dos mortos, garantindo que o julgamento fosse compassivo (NG, 2017, p. 157).

O bodhisattva Ksitigarba passa a ser a figura central dos seis renascimentos, mesmo que ele apareça apenas uma vez na Escritura dos Dez Reis dos Infernos (NG, 2017, p. 151), tornando Yama um de seus assessores, junto com os outros dez reis (SIKLÓS, 1996, p. 182). Isso pode ser visto tanto na imagem do séc. $\mathrm{X}$ apresentada aqui (fig. 8), como em outras, nas quais Ksitigarbha está no centro, rodeado pelos dez reis. Na representação de Ksitigarbha do Turquistão, utilizada nesse artigo, ele aparece rodeado pelos dez reis, sendo Yanlou encontrado no canto inferior direito, perto de onde vemos também o espelho do karma e o assistente com cabeça de búfalo.

\section{Conclusão}

A absorção de Yama pelo budismo seguiu diversas formas quando se compara literatura e imagens. O Yama literário segue um caminho canônico complexo desde antes dos Vedas até os Sutras e Tantras budistas. O budismo adotou Yama transformando o simbolismo e suas características para adequar ao seu sistema. Mesmo assim sua transmutação que vai desde um rei que rege os mortos e ancestrais, passando por um bodhisattva que busca ajudar os seres a sair da existência degenerativa, e tornando-se até mesmo um juiz burocrata sem tanta soberania quanto tinha em seus primórdios, não abandona completamente suas representações visuais anteriores, permitindo uma maior possibilidade interpretativa e reflexiva dessa divindade no budismo.

Mesmo que as duas construções, literária e imagética, ocorram em paralelo, não é possível dizer que são a mesma, que uma reflete exatamente a outra. A construção imagética tem um poder de síntese comparável só ao 
poder de explanação da construção literária. Yama das imagens, sintetiza não só a cultura local, mas as influências que as alcançaram, mantendo aspectos iconográficos, que poderiam ter sido ignorados ou obliterados pelos artistas. Além disso, nelas são somadas influências outras, que não de textos diretamente vinculados a Yama, mas que indiretamente trata de assuntos significativos para reflexões a respeito da morte, renascimento, impermanência e interdependência.

\section{Referências}

DHARMATRATA. Coleção dos Versos Indicativos: Udanavarga de Dharmatrata. Tradução e Adaptação: TSAI, Plínio Marcos; CASTRO, Ana Cristina. Valinhos: ATG, 2018.

FAURE, Bernard. Indic Infuences on Chinese Mythology: King Yama and his Acolytes as Gods of Destiny. In: KIESCHNICK, John; SHAHAR, Meir. India in the Chinese Imagination: Myth, Religion, and Thought. Philadelphi: University of Pennsylvania Press, 2013.

FRÉDÉRIC, Louis. Buddhism: Flammarion Iconographic Guides. Paris: Flammarion, 1995.

NG, Zhiru. The making of a savior bodhisattva Dizang in medieval China. Honolulu: University of Hawai'i Press, 2017.

PANOFSKY, Erwin. Estudios sobre iconologia. Alianza Editorial. Madri, 1972.

Rg-Veda, trad. Ralph T. H. Griffith (1896), do “The Rig Veda,” Internet Sacred Text Archive, acessado 19/07/19, http://www.sacred-texts.com/hin/rigveda/.

SIKLÓS, Bulcsu. The Evolution of the Buddhist Yama, in The Buddhist Forum, ed. Tadeusz Skorupski, London: SOAS, vol.4 (1996).

TEISER, Stephen F. Having Once Died and Returned to Life: Representations of Hell in Medieval China. In: Harvard Journal of Asiatic Studies, vol. 48, n 2. Cambridge: Havard-Yenching Institute, 1988.

TEISER, Stephen F. The Ten Kings of Purgatory and Popular Belief. Princeton: Princiton University Press, 1993.

TEISER, Stephen F. The Wheel of Rebirth in Buddhist Temples. In: Arts asiatiques, tome 63, 2008.

TSAI, Plínio Marcos. A Meditação Budista Indiana. Valinhos: ATG, 2017 a.

TSAI, Plínio. Cerimônia do Uposatha: de acordo com o Pratimoksa Mulasarvastivada. Valinhos: ATG, 2017b.

TSAI, Plínio Marcos. História da Tradição Budista Indiana. Valinhos: ATG, 2017c.

TSAI, Plínio Marcos. Meditações: A vida do Buddha. Valinhos: ATG, 2017d.

TSAI, Plínio (org). Sutra do Bodhisattva Ksitigarbha. In: Buddhanusmrti. Valinhos: ATG, SP, 2016. WHITNEY, William Dwight (trad.). Atharvaveda-sambita. Cambridge: Harvard University, 1905. 


\section{Maximiliano Augusto Sawaya}

Helmut Renders

WÖLFFLIN, Heinrich. Das Erklären von Kunstwerken. Mit einem Nachwort des Verfassers. Leipzig: Verlag E. A. Seemann, 1940.

WÖLFFLIN, Heinrich. Kunstgeschichtliche Grundbegriffe. Das Problem der Stilentwickelung in der neuern Kunst. München. Bruckmann, 1915.

Submetido em: 29-12-2019

Aceito em: 23-5-2020 